\title{
Little seed canary grass (Phalaris minor Retz.) promoting own growth functional traits but suppressing of wheat crop (Triticum aestivum L.) at vegetative stage: An ecological assessment
} Amandeep Kaur, Ram Chand, A.N. Singh*

Department of Botany, Panjab University, Chandigarh-160014, India.

Received: 9/17/2017; Accepted: 9/29/2017

\begin{abstract}
Weed-crop interaction in the agro-ecosystems is a serious biological concern which hampers production and yield of the crops. Present study conducted to assess growth functional traits of selected weed and crop species under weed-crop interaction experiment that was established in a Latin square matrix model (LSM) in the backside of Department of Botany in a fenced dome. We investigated the ability of little seed canary grass that how it suppresses wheat crop growth at vegetative stage under mono- and mixed culture combinations. Data sampling for selected growth traits (Shoot height, Leaf area and Tiller number) were monitored at different temporal days after seed sowing (30-, 60-, 90- and 120 DAS). Results indicated that at initial stage (30 DAS), wheat exhibited significantly better growth (more leaf area and shoot height than little seed canary grass) under both combinations (Mono- and Mixed culture); however, little seed canary grass (Phalaris minor) suppressed both traits of wheat (leaf area and shoot height) due to interspecific competition. After 30 DAS, however little seed canary grass switched own growth traits in increasing mode therefore shoot height and leaf area were increases till 120 DAS, while, growth traits of wheat crop was significantly suppressed. Since, a linear trend was observed in the growth traits particularly shoot height with respect to days after sowing. Therefore, a significant relationship between growth traits and days was developed under both combinations that evidently indicated impact of little seed canary grass on suppression of wheat crop. In conclusion, wheat crop growth seriously undergo suppression due to little seed canary grass as inter-specific competition at least from initial stages of growth while growth traits of little seed canary grass less affected in competition which may be act as facilitation for weed under weed-crop interactions.
\end{abstract}

Keywords: Wheat, Little seed canary grass, Shoot height, Leaf area, Tillers

\section{Introduction}

Wheat (Triticum aestivum L.) is the staple food for more than one third of world population and one of the most consumed cereal crop in India (Fatima et al., 2014, Tufail et al., 2014). Wheat is grown on nearly 12 million ha in rotation with rice (another staple crop) in Indo-Gangetic plains of South Asia (Malik et al., 1998). But its production directly affected by many factors including problems of weeds that causes significant yield losses. Several estimates reported in the literature to show a wide range which varied from 30 to $50 \%$ based on weed infestation (Pandey et al., 1997, Chhokar et al., 2006). Weed competition (inter-specific) is one of the most significant constraints which affect the crop production substantially (Siddique et al., 2010). When weeds emerge earlier than the crop, they grow in close proximity, as their shoot or root system overlap and it becomes severe due to more smothering effect (Paswan et al., 2017). Although, such information is not very new as many reports have been reported earlier on the suppressing ability of weeds on crop (Bhowmik and Doll, 1992; Javaid et al., 2007). In general, weed stress on crops basically relies upon the competitive capacity of a crop through its different physiological and morphological traits that permits the crop plant to

${ }^{*}$ Corresponding Author:

Dr. A. N. Singh,

Department of Botany, Panjab University,

Chandigarh-160014, India..

E-mail: ansingh@pu.ac.in utilize light, water, space, and nutrients efficiently in the presence of a weed. But, specifically, any weed plant when enter in the domain of a crop land either by any mean of dispersal mechanism preferably construct certain structural and functional traits which might be more effective and powerful than that of crop traits, therefore, structural and functional modifications promote more feasible condition to the extent of successful invasion. Thus, after invasion, a crop plant enters into a big challenge for space, nutrients and light. Study regarding trait-based weed-crop interactions are conspicuously lacking in literature, therefore, require massive information to understand its complex mechanism (Pakeman et al., 2015).

Out of all the weeds present in India, Phalaris minor (Retz) - little seed canary grass is one of the most predominant and troublesome annual grassy weed of wheat (Bir and Sidhu, 1979, Malik et al., 1981, Singh et al., 1995, Bhan and Kumar, 1997, Chhokar et al., 2008, Chhokar and Malik, 2002, Mehra and Gill, 1988, Balyan and Malik, 2000) commonly known by several names in India (given in Table 1). Wheat yield losses especially from this weed $(P$. minor) estimated as about with 15-50\% (Malik and Singh, 1995, Gaofeng et al., 2010, Kaur et al., 2012, 
Khera et al., 2012, Singh et al., 2012), but these estimated values are somewhat varies from report basis, for example, $25-50 \%$ reported by Bhan and Sushil Kumar, 1998; according to him, it may go up to $80 \%$ to total in very severe cases. The competition ability of this weed is perhaps due to its morphology and their growth strategy, which is probably more or less similar to those of wheat crop (Singh et al., 1999). Moreover, this weed plant perhaps shows a crop mimicry (i.e. unable to be differentiated from the crop at early growth stages) that could not be possible to distinguish with wheat crop (Ranjit et al., 2009). In this amalgamated situation, farmers/cultivators are unable to distinguish this weed. Moreover, its morphological similarity with wheat at vegetative growth stage, high density, ability to tiller freely, similar growth period as with crop, high reproductive potential, earlier shedding of seeds and ability of seeds to remain dormant in the soil for several years are promoting for its strong competitive ability and degree of invasiveness (Duary and Yaduraju, 2005). Characteristically, comparisons between leaf area, plant height, above and below ground dry weight (Radosevich et al., 1997, Lovelli et al., 2010) and tillering capacity, specific leaf area, biomass accumulation etc. (Malik and Singh, 1993, Ni et al., 2000, Mason et al., 2007, Saito et al., 2010, Sardana et al., 2017) have been used to provide information to explain aggressiveness of the species with respect to its competitive ability. But, there is limited information on the trait approaches ecophysiological basis of the ability of this plant species to outcompete with the other species.

Since plant height is an important functional trait for determining the growth and competition ability of the crop with respect to weed-crop competition which reflects the suppression capacity of the crop (Sharma, 2011, Zystro et al., 2012). Another trait i.e.
Leaf area which is also a good parameter of crop growth and is effective trait provide satisfactory information to understand assimilating capacity of a crop. In addition to this, number of tillers which reflect the establishment of crop, canopy structure and also the yield to be obtained from the crop, so these are the direct indicators of vegetative growth progress of crops (Mehmood et al., 2014). The weed competes with the crop for light, nutrient and space, thereby suppressing crops efficiency which in turn affecting significantly on production and yield. So, how, weed-crop interactions could be explained with respect to functional approaches of traits is perhaps the main objective of our study conducted intensively. However, in this paper, we discuss about performance of those three selected growth traits (shoot height, leaf area and number of tillers) in relation to spatio-temporal (days after sowings, DAS) response under both combinations (monoculture and mixed-culture) are discussed to give answer of the following questions:

(1) How and when Phalaris minor (Retz.) promoting their growth than wheat crop? If yes, then which time and in which combination, this would suppress more significantly growth of wheat crop?

(2) How and which extent selected vegetative growth traits will be an effective tool to predict the competitive ability of the weed either in mono-or mixed combinations?

(3) Is there any trend related direction with respect to DAS was followed by little seed canary grass to suppress growth performance of wheat crop under weed-crop interactions?

(4) Since, vegetative growth traits especially shoot height exhibit a linear growth projection with respect to increasing time by any plant in any habitat. Is such trend really exhibited under weed-crop interactions by both plant species?

Table 1. General characters of wheat crop and little seed canary grass.

\begin{tabular}{lll}
\hline \multicolumn{1}{c}{ Characters } & \multicolumn{1}{c}{ Wheat } & \multicolumn{1}{c}{ Little seed canary grass } \\
\hline Botanical name & Triticum aestivum $\mathrm{L}$. & Phalaris minor Retz. \\
Common name & Gehun, Godhi, godumai, godumbaiyarisi, \\
& godumalu, Gehu and kanakk & $\begin{array}{l}\text { little seed canary grass, small-seeded canary grass, small } \\
\text { canary grass, lesser-canary grass, sittee booti, Gehusa, } \\
\text { Gullidanda and Gehun ka mama }\end{array}$ \\
Life form & Annual & Annual or perennial \\
Family & Poaceae & Poaceae \\
Plant height & $85-120 \mathrm{~cm}$ (approx.) & $90-150 \mathrm{~cm}$ (approx.) \\
Basal node & Greenish yellow & Pink in color at 50 days of growth \\
ligule & Very small & Three times larger than wheat \\
Auricle/leaf ears & Two leaf ears/auricles and hairy & No auricle \\
Leaf color & Dark green & Light green \\
Leaf size & $20-45 \mathrm{~cm}$ long and $0.9-1.3 \mathrm{~cm}$ broad (approx.) & $10-50 \mathrm{~cm}$ long and $0.2-1.4 \mathrm{~cm}$ broad (approx.) \\
Tillering & Erect & Rossete \\
Tiller branching & No branching & Tiller branching \\
Number of seeds & $60-70$ seeds per plant & $10000-30000$ seeds per plant \\
Grains length & $12-22$ mm approx. & $1-2.5$ mm long x 1.2 mm wide \\
Seed colour & Red or amber & Dark brown \\
Seed shape & Oval and hard & Oval and smaller in size \\
\hline
\end{tabular}

\section{Materials and Methods}

Present study was conducted during the Rabi season (November to April) of 2016-2017 in the experimental dome of Department of Botany (back side), Panjab University, Chandigarh, India, which is located at $30.7601^{\circ} \mathrm{N}$ latitude and $76.7663^{\circ} \mathrm{E}$ longitude. The climate of the experimental area is humid subtropical. The maximum temperature during this season is $16^{\circ} \mathrm{C}$ to $25^{\circ} \mathrm{C}$, while the minimum temperature being $9^{\circ} \mathrm{C}$ to $18^{\circ} \mathrm{C}$. The 
average annual rainfall is $1100 \mathrm{~mm}$. The experimental design was established as Latin Square Matrix (LSM) for monitoring of those growth traits (Figure $1 \mathrm{~A}$ and Figure 1B). Size of each plot $(45 \mathrm{~cm}$ $\mathrm{X} 45 \mathrm{~cm}$ ) was maintained into three replicates for each combination. Therefore, total number of nine plots was maintained to monitor intensively to record data of selected growth functional traits wheat and little seed canary grass under both combinations. Tested seeds used for experiment were collected from Hisar Agricultural University, Haryana. Weight of pre-sown seeds were weighed by digital electronic fractional weight balance, and then sown into the marked plots separately under both combinations in respective plots. All sown plots were carefully marked with different colored flags which were fixed at top with one meter long iron thin rod (diameter about $0.02 \mathrm{~cm}$ ) inserted in each plot. The soil of the experimental plot was sandy loam in texture with $\mathrm{pH} 7.72$; at the time of seed sowing, water holding capacity (WHC) was $36.7 \%$ and bulk density was $1.17 \mathrm{gcm}^{-3}$ which is in general required for crop cultivation in sub-tropical climate. The Physico-chemical properties of experiment soil were total soil organic C $(1.14 \%)$, total kjeldahl $\mathrm{N}(0.22 \%)$ and total soil $\mathrm{P}(0.35 \%)$.

In order to get maximum seedling emergence, the soil depth of seed was sown at 4 to $5 \mathrm{~cm}$. According to the experimental design, total two combinations were prepared i.e. monoculture (100 percent of Triticum aestivum L. and 100 percent of little seed canary grass were sown in a separate plots) whereas mixed-culture plots were established as 50:50 ratio of wheat + little seed canary grass in their respective plots. Data sampling and observations of selected growth traits were carried out at different spatiotemporal time (i.e. days after sowing, DAS) of weed and wheat crop under both combinations. The growth functional traits are shoot height $(\mathrm{cm})$; Number of tillers per plant and leaf area $\left(\mathrm{cm}^{2}\right)$ was monitored at 30 DAS, 60 DAS, 90 DAS and 120 DAS, respectively. Shoot height was measured at ground level to the maximum leaf tip using by a measuring tape. The numbers of tillers were counted per plant manually within the respective plots. Leaf area $\left(\mathrm{LA}, \mathrm{cm}^{2}\right)$ of the plant was calculated after measuring Leaf length (LL) and maximum leaf width (LW) of fifteen leaves of each respective plot then calculated by using formula (Quarrie and Jones, 1979; Aldesuquy et al., 2014):

\section{Leaf area $=\mathbf{L L} * \mathbf{L W} * \boldsymbol{k}$}

Whereas, LA= leaf area, LL= leaf length $(\mathrm{cm})$ and $\mathrm{LW}=$ leaf width $(\mathrm{cm})$, and $k$ (constant $)=0.75$.

\section{Statistical analyses}

SPSS-PC statistical software was used for all statistical analyses. To observe effect of combinations such as monoculture and mixed culture on growth traits of wheat and weed (little seed canary grass), the data were subjected to
General Linear Model (GLM) for analysis of variance (ANOVA). Whereas, mean values of shoot height, leaf area and number of tillers were tested for difference among combinations with Tukey's honestly significant difference (HSD) mean separation test (SPSS, 2005, version 14.0). In order to find out linear growth relationship, collected data of all growth functional traits (in replicate) were subjected to develop a linear relationship with DAS and growth traits under both combinations.

\section{Results and Discussion}

\section{Effect of combinations}

Shoot height: Height is an important structural characteristic growth parameter to assess growth functional traits of a plant. In order to understand the competitiveness of wheat against little seed canary grass, some workers have reported on this trait (Mahajan and Brar, 2002, Noshadian et al., 2014, Sardana et al., 2017). In present study, at monoculture, shoot height was significantly varied due to combination and DAS, whereas, maximum shoot height recorded $96.17 \mathrm{~cm}$ in wheat and $117 \mathrm{~cm}$ by little seed canary grass at 120 days after sowing (DAS), while respective values were minimum $36.87 \mathrm{~cm}$ for wheat $22.4 \mathrm{~cm}$ by little seed canary grass at 30 DAS, respectively (Figure 2 and Table 2).

Corresponding parameter at mixed culture combination showed an interesting trend i.e. little seed canary grass significantly suppressed the shoot height of wheat while their own growth was remarkably maintained in better format which appeared substantially better than wheat. It is probably due to a significant suppression effect given to the wheat crop. Analysis of variance (ANOVA) revealed significant differences due to combination and DAS; due to this, its combination was also significantly different (Table 2). In general, shoot height of both plants (weed and crop) showed a linear projection with respect to the increasing time (days after showing) up to the 120 DAS, therefore, highest values were attained by wheat $(86.34 \mathrm{~cm})$ and by little seed canary grass $(102.34 \mathrm{~cm})$ at 120 days after sowing, whereas, minimum was recorded in wheat $(32.47 \mathrm{~cm})$ and its half by the canary grass $(16.34 \mathrm{~cm})$ at 30 DAS at mixed culture. However, a remarkable trend was found which clearly shown in between monoculture and mixed culture, the height of wheat face suppression as due to the competition given by little seed canary grass started from 30 to 120 DAS. However, highest reduction in wheat was observed at 60 days (23\%) followed by 30,120, 90 days after sowing (DAS), respectively. In this study, maximum amplitude of suppression by canary grass on wheat crop was found at 60 days after sowing indicates that probably this time is the peak growth period of the weed-crop to synthesize maximum carbohydrates via photosynthesis to construct structural component (e.g. shoot, root and tillers) to 
utilize maximum amount of nutrients, water and space that would allocate substantial amount to the reproductive component inflorescence. Evidently, Chaudhary et al., 2008 from Pakistan found that the critical period of weed- crop competition (wheat and canary grass) was observed in 30-50 day after sowing. This might be due to the contrasting pattern was found in the growth between both combination. Moreover, our results are in conformity with the findings of Singh et al., 2017 (India) who reported a significant decrease in shoot height of wheat under mixed-culture combination with Phalaris minor (canary grass) after respective DAS. It shows that Phalaris minor has have more competitive ability as the weed has comparatively better growth efficiency in shoot height than the crop as supported by Bogale et al., 2011 from Ethiopia, Yaduraju and Ahuja, (1997) and Sinha et al., 2009.

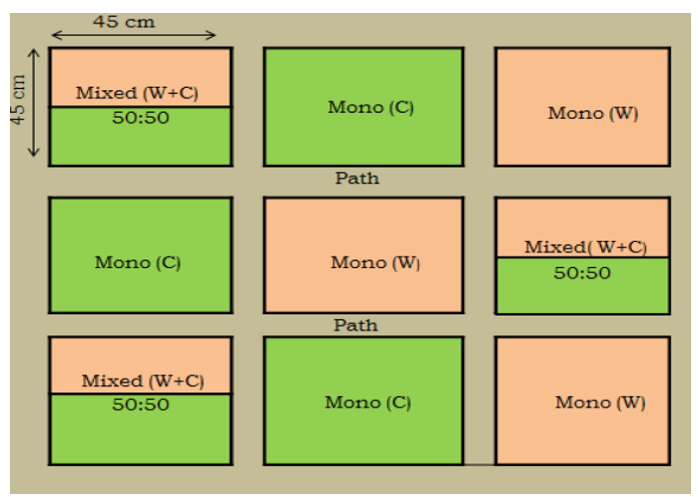

Figure 1. (A) Experimental Design of present study established as Latin Square Matrix (LSM) at research site. Size of each plot $(45 \mathrm{~cm} \mathrm{X} 45 \mathrm{~cm})$ was fixed and maintained into three replicates for each combination. $(\mathrm{W}=$ Wheat, Mono $=$ monoculture, Mixed $=$ mixed-culture, $\mathrm{C}=$ canary grass (little seed) and $\mathrm{W}+\mathrm{C}=$ wheat + Canary grass (little seed)).

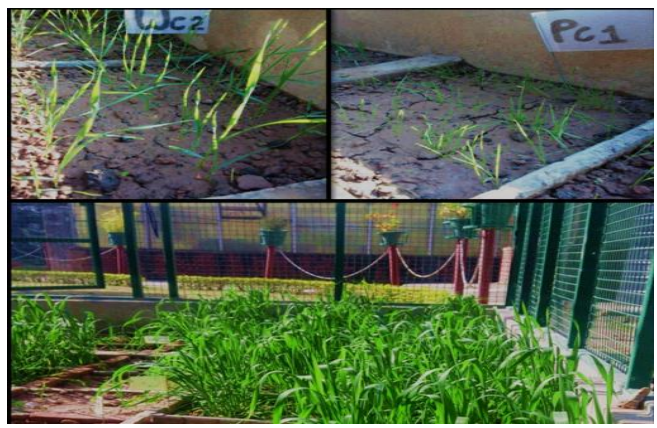

Figure 1(B). Experimental Design established as Latin Square Matrix (LSM) showing respective wheat and canary grass plots

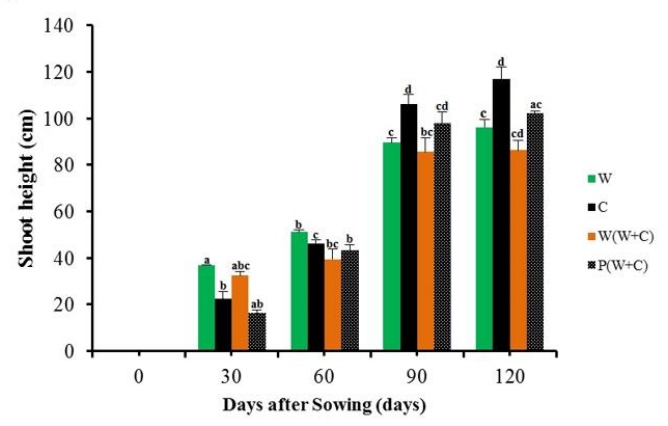

Figure 2. Effect of combinations (Mono- and mixed-culture) of weed crop interactions on Shoot Height with Days after Sowing (DAS) (bar represented means of three replicates \pm 1 standard error, SE, $n=3$ ). Values of vertical bars with different letters are significantly different with each other at $\mathrm{p}<0.05$.

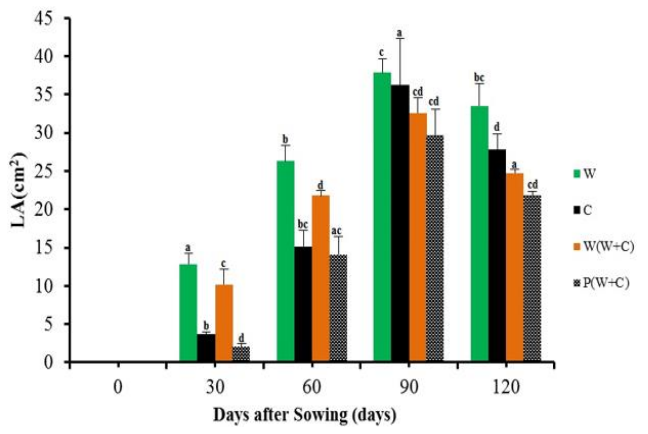

Figure 3. Effect of combinations (Mono- and mixed culture) of weed crop interactions on Leaf area (LA) with Days after Sowing (DAS) (bar represented means of three replicates \pm 1 standard error, SE, $n=3$ ). Values of vertical bars with different letters are significantly different with each other at $\mathrm{p}<0.05$.

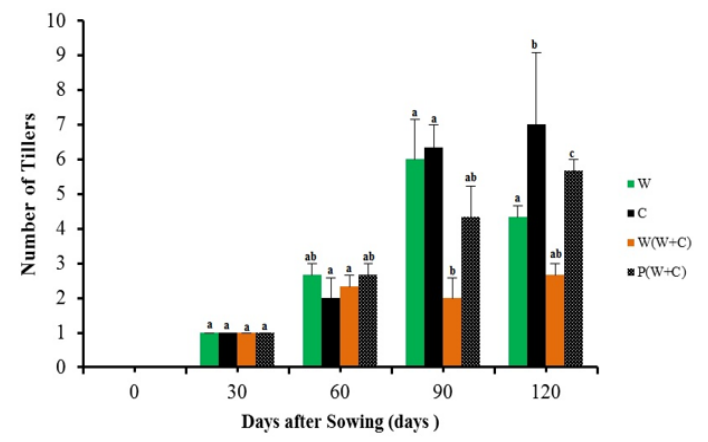

Figure 4. Effect of combinations (Mono- and mixed-culture) of weed crop interactions on Number of tillers with Days after Sowing (DAS) (bar represented means of three replicates \pm 1 standard error, SE, $n=3$ ). Values of vertical bars with different letters are significantly different with each other at $\mathrm{p}<0.05$. 
Table 2. Summary of ANOVA results for selected Plant functional traits taken as growth traits (Shoot height, Leaf area and Number of tillers) in this study.

\begin{tabular}{ccccccc}
\hline \multirow{2}{*}{ Source } & Dependent Variable & df & Sum of Square & Mean square & F & Statistics- $\boldsymbol{p}$ \\
\hline \multirow{2}{*}{ Combination } & SH & 3 & 743.401 & 247.800 & 9.531 & .000 \\
\multirow{2}{*}{ DAS } & LA & 3 & 568.520 & 189.507 & 15.279 & .000 \\
& NT & 3 & 22.183 & 7.394 & 5.995 & .002 \\
\multirow{3}{*}{ Combination } & SH & 4 & 90662.683 & 22665.671 & 871.757 & .000 \\
\multirow{3}{*}{ Residual } & LA & 4 & 9375.728 & 2343.932 & 188.985 & .000 \\
& NT & 4 & 228.333 & 57.083 & 46.284 & .000 \\
& SH & 12 & 2478.365 & 206.530 & 7.943 & .000 \\
& LA & 12 & 316.124 & 26.344 & 2.124 & .037 \\
& NT & 12 & 44.733 & 3.728 & 3.023 & .004 \\
& SH & 40 & 1040.000 & 26.000 & & \\
\end{tabular}

SH- Shoot Height, LA-Leaf area, NT-Number of tillers
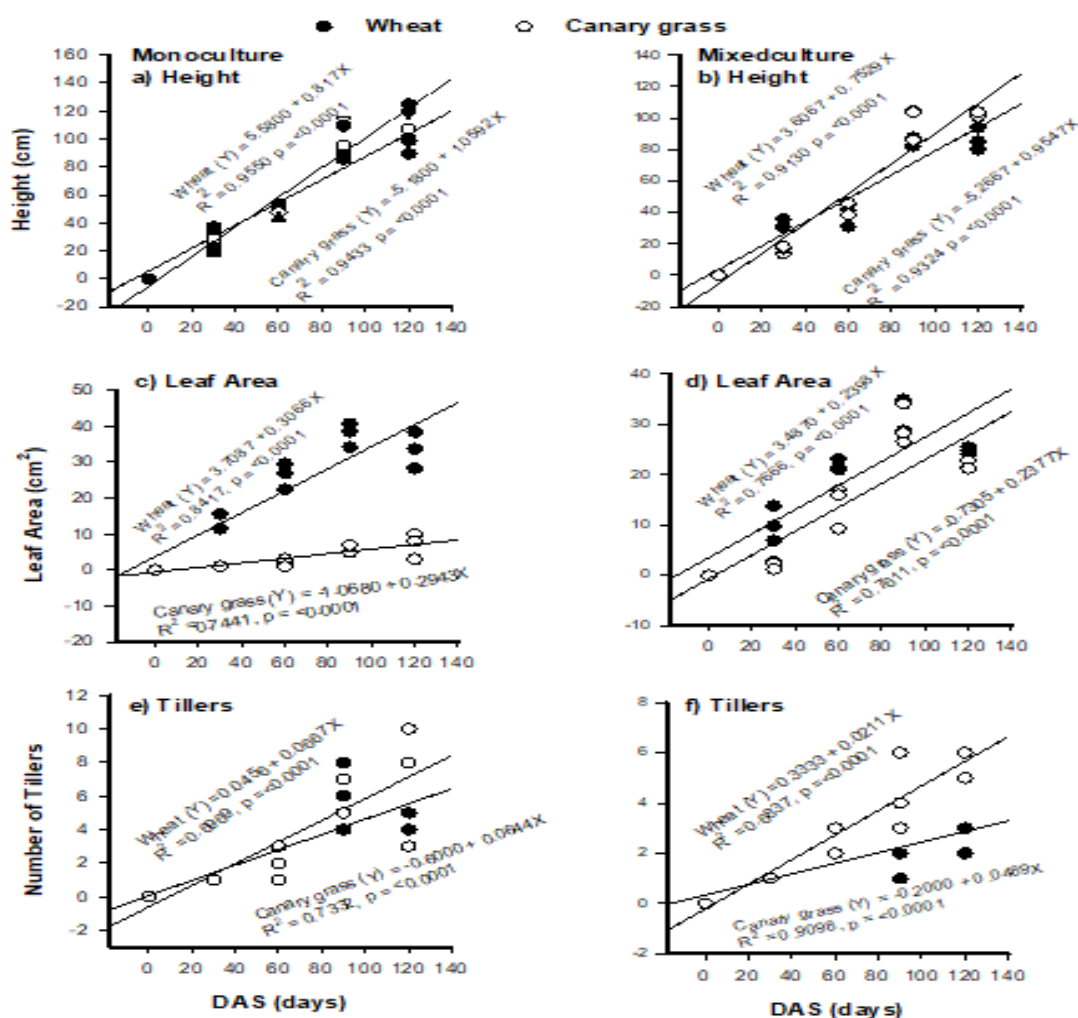

DAS (days)

Figure 5. Relationships between days after sowing (DAS) with vegetative growth traits of wheat crop and canary grass under monoculture and mixed culture combinations. Figure- $5 \mathrm{a}$ and $-5 \mathrm{~b}$ for mono- and mixed-culture shoot height, whereas $-5 \mathrm{c}$ and $-5 \mathrm{~d}$ is for leaf area and $-5 \mathrm{e}$ and $-5 \mathrm{f}$ represented as number of tillers, respectively.

\section{Leaf Area}

In this study, under monoculture, maximum leaf area estimated by wheat crop $37.84 \mathrm{~cm}^{2}$ and weed plant (little seed canary grass) $36.25 \mathrm{~cm}^{2}$ at 90 DAS; whereas, minimum values for corresponding parameter was estimated as $12.86 \mathrm{~cm}^{2}$ of wheat and three times lower size i.e. $3.67 \mathrm{~cm}^{2}$ for little seed canary grass at 30 days after sowing (Figure 3). Perhaps, leaf breadth and length in little seed canary grass at initial stage of growth does not prefer more investment of photosynthetic product in construction of leaf thickness and broadening of leaf size, it might be its species-specific properties. Due to increasing mode of leaf area with respect to time, values of leaf sizes of weed plant (little seed canary grass) and wheat crop were significantly increased with respect to increases days after sowing time (DAS). Therefore, both factors (combination and DAS) and their interactions were significantly different with leaf area (Table 2). Probably, at initial period of vegetative growth of weed plant (little seed canary grass) tended to manufacture more in number of leaf rather than widening of single leaf. Therefore, smaller size of leaf area might found at early growth stage. It seems that little seed canary grass trying to prepare more competitive abilities at least from initial growth stage where crop plant is not yet to ready face inter-specific competition. Evidently, in mixed combination, a significant competition was given by little seed canary grass on wheat crop; therefore, leaf area of wheat crop was 
substantially suppressed. However, a leaf area value of wheat crop was in better range than little seed canary grass. Maximum leaf area of wheat (32.61 $\mathrm{cm}^{2}$ ) was estimated and of little seed canary grass $\left(29.69 \mathrm{~cm}^{2}\right)$ at 90 DAS whereas minimum was estimated at 30 -DAS time of wheat $\left(10.19 \mathrm{~cm}^{2}\right)$ and for little seed canary grass $\left(2.04 \mathrm{~cm}^{2}\right)$ (Figure 2) under mixed culture. Due to impact of combination, a remarkable trend was found that clearly indicated the difference between monoculture and mixed combination, leaf area of wheat was reduced from monoculture as due to the weed competition given by little seed canary grass in mixed combination; this suppression was initiated even from 30 DAS till the period of 90 DAS and highest reduction was observed at 120 days after sowing $(26 \%)$ followed by 30, 60 and 90 DAS, respectively. Little seed canary grass was fairly grown in the monoculture and thus tended to maximize efficiency; it has been observed suppression of leaf area of wheat in mixed combination indicating strong capabilities of interspecific competition. ANOVA also revealed a significant effect of combination and DAS. Therefore, values were significantly varied under mono and mixed combination with respective time of sowing (Fig. 2 and Table 2). Present results are comparable in accordance with findings of Iqbal and Wright, 1999 (Bangor, U.K.) and Prasad Babu and Jain, 2012 (M.P, India) in which they found that canary grass decrease the leaf area of wheat in competition (mixed culture) from the individual grown (mono-culture) wheat crop.

\section{Number of Tillers}

Number of tillers is also one of the structural traits by which predict efficacy of a plant growth quality that would have been correlated with production efficiency, therefore, information regarding tillering under various crop-weed competition as well as productivity of crop is however available in the literature (Ramesh et al., 2017), but interactions of wheat crop with little seed canary grass in the face of trait based is not clearly understood. In our study under monoculture combination, maximum number of tillers were produced by wheat (6.00) after 90 DAS while little seed canary grass produced slightly more in number of tillers (6.50) at 90 DAS and increases maximally up to (7.00) after 120 DAS while wheat remained in number as of at 90 DAS. However, ANOVA exhibited significant differences due to combination and DAS. Therefore, corresponding parameter in mixed combination, were significantly varied due to DAS thus reflected an increasing tiller number with time, for example, maximum tillers were attained by wheat (2.67) and by little seed canary grass (5.67) at 120 days after sowing and minimally recorded by wheat (2.00) after 90 DAS and (2.67) by weed at 60 DAS (Figure 4). A significant trend was found which clearly shown the contrasting difference between monoculture and mixed culture, the number of tillers of wheat undergo suppression as due to the competition given by little seed canary grass since 90 to 120 days after sowing, but highest reduction of tillers were observed at 90 days after sowing $(67 \%)$ followed by 120 and 60 days after sowing respectively in wheat-weed competition. However, Summary of outcomes of ANOVA reveals the effect of combination is statistically significant variation (Figure 4 and Table 2). In this study, a remarkable trend was observed for little seed canary grass which attended substantially better tillering growth from wheat by interspecific competition by little seed canary grass which significantly suppressed the number of wheat tillers. It occurs due to the incompatible pattern was found in the tillering growth between in both combinations. Our results are in full agreement with those observed by Chaudhary et al., 2008, Jadho and Nalamwar, 1993, Mehmood et al., 2014. However, some studies are in the same direction (Rajput et al., 1987, Chaudhary et al., 2008) reported that weeds shows less suppression to growth and yield of wheat crop growth up to 30 days after sowing (DAS), but after that, with increases period, little seed canary grass further decreased the wheat growth significantly. This might be due to uniform plant distribution which resulted in better utilization of available resources and can primarily be attributed to a decrease in tillering by weed competition. Tillers production of a plant in cereals is related with the suppression of weeds growing in association with it (Sharma, 2011). In our study, dominating weed $P$. minor (little seed canary grass) exhibited more tillers per plant than wheat under non-competitive conditions which was in conformity with observation reported by Singh et al., 1999.

\section{Relationships of Growth Functional Traits with Time (DAS)}

In this study, a significant linear relationship with growth traits (shoot height, leaf area and number of tillers) of wheat crop and weed plant under both combinations with days after sowing (DAS) was developed (Figure 5a-f). An interesting result was found in monoculture; under this combination, wheat crop reflected a close linear relationship and revealed high level of coefficient variation and probability values $\left(\mathrm{R}^{2}=0.9550, \mathrm{p}=<0.0001\right)$ which was little bit more than that of little canary seed grass $\left(\mathrm{R}^{2}=0.9433, \mathrm{p}=<0.0001\right)$ indicated that wheat crop could grow and yield in better form without facing any level of competition at growth stage (Figure 5a). This kind of trend even found for little seed canary grass under same combination, therefore, values for probability level and coefficient variation was more or less similar with wheat crop further indicates that a weed plant can utilize abiotic resources with maximum mode of efficiency for their growth and development. Moreover, its competitive ability and better utilization efficiencies providing an array to grow more luxuriously either alone or in combined with any crop plant. 
Interestingly, under mixed combination, corresponding relationship showed a suppression effect in the wheat crop due to competition by little seed canary grass, therefore, values for coefficient variation in the wheat crop $\left(\mathrm{R}^{2}=0.9130, p=\right.$ $<0.0001)$ was comparatively lower from weed plant $\left(\mathrm{R}^{2}=0.9324, p=<0.0001\right)$ statistically confirming a competitive effect of weed plant on wheat crop in the field (Figure 5b). In agreement with this, few workers (Yadav and Dhanai, 2017; and Babu et al., 2017) have reported that shoot height is directly proportional to the days after Sowing (DAS) in both combinations with strong suppression on wheat crop by little seed canary grass.

Leaf area predicts the photosynthates production and resource accumulation. It is depend upon the light absorption, diffusion pathway of carbon dioxide and tissue development. Leaf area exhibited weak relationship and less important in suppressing weed biomass but has strong effect on seed production (Bogale et al., 2011) but many researchers have also been reported the positively correlation of leaf area with high competitive ability against weeds under competitive pressure (Lemerle et al., 1996; Seavers et al., 1999). In present study, a linear relationship between leaf area and days after sowing (DAS) is developed under both combination but level of linearity, values for correlation coefficient and probability were significantly varied for wheat and little seed canary grass. For example, wheat crop under monoculture combination showed strong relationship $\left(\mathrm{R}^{2}=\right.$ 0.8417, $p=<0.0001)$ than little seed canary grass $\left(\mathrm{R}^{2}=0.7441, p=<0.0001\right)$ indicates expansion of leaf area in wheat crop tended to capture more space, to enhance nutrient foraging efficiency and crown projection when no competitor if available. Although, corresponding relationships under mixed combination, wheat crop showed a significant linear relationship with more correlation coefficient values $\left(\mathrm{R}^{2}=0.7666, p=<0.0001\right)$ than little seed canary grass $\left(\mathrm{R}^{2}=0.7611, p=<0.0001\right)$ indicating wheat crop has suppression due to impact of combination on leaf area therefore correlation coefficient was slightly lower from mono culture combination while little seed canary grass exhibited higher values of correlation coefficient $\left(\mathrm{R}^{2}\right)$ under mixed combination than mono culture combination (Figure 5c and 5d).

Tillering in wheat determines plant canopy size, photosynthetic area and, more importantly, the number of spikes bearing grains at maturity (fertile shoots), which is a key component of yield. This could be due to the greater cell division and more meristematic activity for the formation of tillers which would directly influence the growth and attributing characteristics through better utilization of photosynthesis. In this study, we found significant relationships between numbers of tillers with days after sowing (DAS), in wheat crop under mono and mixed culture combination, tiller numbers had least variation in the values of correlation coefficient $\left(\mathrm{R}^{2}=0.6969, \mathrm{p}=<0.0001\right)$ in monoculture, $\left(\mathrm{R}^{2}=0.7837, \mathrm{p}=<0.0001\right.$ in the mixed combination) reflecting tiller initiation in the wheat crop is presumably regulated by some other factors. Because little seed canary grass responded a close relationship under mixed combination with highest correlation coefficient values $\left(\mathrm{R}^{2}=0.9098\right.$, $\mathrm{p}$ $=<0.0001)$ from monoculture $\left(\mathrm{R}^{2}=0.7332, \mathrm{p}=\right.$ $<0.0001)$ showed little seed canary grass has have an intrinsic property of inter-specific traits that could have been utilized in the invasion of wheat crop field (Figure 5e and 5f).

\section{Conclusions}

There is no conspicuous lacking of the information regarding weed-crop interactions traditionally in the literature but trait based knowledge of weed-crop is not fully understood, therefore, it has been considered as thrust area of research today in agroecology. This could be applied in agriculture to get information on functional attributes of crop-weed interactions. Via trait based analyses of important functional attributes like growth, reproduction and dispersal mechanism of weed-crop could be useful for understanding its mechanistic approaches.

In present study, we found that weed Phalaris minor Retz. (Little seed canary grass) enhances its growth traits (plant height and number of tillers), but suppress growth of the wheat crop in mixed combination indicating significant impact of suppression by little seed canary grass. Further, it has been observed that, growth of wheat crop is mainly suppressed by increasing number of tillers and shoot height of little seed canary grass because it occupies more area and increase height of shoot height that inhibited the light intensity of wheat crop that could be augmented with significant reduction in the production and yield of wheat crop. In conclusion, wheat crop seriously get threat due to little seed canary grass as inter-specific competition at least from initial stage of growth while growth traits of little seed canary grass not much affected due to competition, this might act as facilitation for weed under weed-crop interactions. Since, present findings are based on a preliminary observation with basic structural growth traits; therefore, more authentic reports will come with intensive study by application and involvement of all kind of traits of weed and crop plant under mechanism of weed-crop interactions.

\section{Competing interests}

Authors declare that they have no competing interests

\section{Authors' contributions}

ANS designed experimental design; AK performed field study, and drafted manuscript, RC helped 
during field and lab study. All authors have equal role in preparation and finalizing the manuscript.

\section{Acknowledgement}

We are very thankful to Chairperson, Department of Botany, Panjab University Chandigarh provided for required facilities during course of work. One of us Master student (Ms. Devina ghai) helped during field study. Amandeep Kaur is gratefully acknowledged to the University Grants Commission, Government of India, New Delhi for financial support in the form of Rajiv Gandhi National Fellowship Award.

\section{References}

1. Aldesuquy H, Baka Z and Mickky B, Kinetin and spermine mediated induction of salt tolerance in wheat plants: Leaf area, photosynthesis and chloroplast ultrastructure of flag leaf at ear emergence. Egyptian Journal of Basic and Applied Sciences 1(2014): 77-87.

2. Babu R, Kakraliy SK, Prakash L, Kumar P and Yadav RA. Effect of Plant Geometry and Seed Rates on Growth, Yield Attributes, Productivity as well as Weed Dynamics of Wheat (Triticum aestivum L.). International Journal of Current Microbiology and Applied Sciences 63.3(2017): 81-88.

3. Balyan RS and Malik RK. New herbicides for Jungali Palak (Rumex retroflexus L.). Indian Journal of Weed Science 32(2000): 86-88.

4. Bhan VM and Kumar S. Integrated management of Phalaris minor in rice-wheat ecosystems in India. In: Proceedings of International Conference on Ecological Agriculture: Towards Sustainable Development, November 15-17 Chandigarh, India. 2(1997): 400-415.

5. Bhan VM and Kumar S. Integrated management of Phalaris minor in rice-wheat ecosystems in India. In: Ecological Agriculture and Sustainable Development. Indian Ecological Society 2(1998): 399-414.

6. Bhowmik PC and Doll JD. Corn and soybean response to allelopathic effects of weed and crop residues. Agronomy Journal 74(1992): 601-606.

7. Bir SS and Sidhu M. Observation in the weed flora of cultivable lands in Punjab-wheat fields in Patiala District. New Botanist. 6(1979): 79-89.

8. Bogale A, Nefo K and Seboka H. Selection of Some Morphological Traits of Bread Wheat That Enhance the Competitiveness against Wild Oat (Avena fatua L.). World Journal of Agricultural Sciences 7(2011): 128-135.

9. Booth BD and Swanton CJ. Assembly theory applied to weed communities. Weed Science 50(2002): 2-13.

10. Chaudhary SU, Hussain M, Ali MA and Iqbal J. Effect of weed competition period on yield and yield components of wheat. Journal of Agricultural Research 46.1(2008): 47-53.

11. Chhokar RS and Malik RK. Isoproturon resistant Phalaris minor and its response to alternate Herbicides. Weed Technology16 (2002): 116-123.

12. Chhokar RS, Sharma RK, Chauhan DS and Mongia AD Evaluation of herbicides against Phalaris minor in wheat in North-Western Indian plains. Weed Research 46(2006): 4049.
13. Chhokar RS, Singh S and Sharma RK. Herbicides for control of isoproturon-resistant Littleseed Canarygrass (Phalaris minor) in wheat. Crop Protection. 27(2008): 719-726.

14. Das TK and Yaduraju NT. Effect of weed competition on growth, nutrient uptake and yield of wheat as affected by irrigation and fertilizers. The Journal of Agricultural Science 133(1999): 45-51.

15. Duary B and Yaduraju NT, Estimation of yield losses of wheat (Triticum aestivum L.) caused by little seed canary grass (Phalaris minor Retz.) competition. Journal of crop and weed 2.1(2005): 8-12.

16. Fatima S, Arshad M, Chaudhari SK, Ali A, Amjad MS and Kausar R. Utilization of synthetics for drought tolerance in bread wheat (Triticum aestivum L.). International Journal of Biosciences 5.1(2014): 104-112.

17. Gaofeng X, Fudou Z and Tianlin L. Biological characteristics, influence on growth of wheat and its economical threshold of Phalaris paradoxa 1 . and Phalaris minor Retz. China Agriculture Science 43(2010): 4409-4417.

18. Godel GL. Relation between rate of seedling and yield of cereal crops in combination with weeds. Scientific Agriculture 16(1995): 165-168.

19. Iqbal J and Wright D. Effects of weed competition on flag leaf photosynthesis and grain yield of spring wheat. Journal of Agricultural Science 132(1999): 23-30.

20. Jadho SL and Nalamwar EV. Response of wheat (Triticum aestivum) genotype to plnating methods and manual weeding. Indian Journal of Agronomy 38(1993): 382-385.

21. Javaid AR, Bajwa N, Rabbani and Anjum T. Comparative tolerance of six rice (Oryza sativa L.) genotypes to allelopathy of purple nutsedge (Cyperus rotundus L.). Allelopatby Journal 20.1(2007): 157-166.

22. Kaur R, Mahey RK and Kingra PK. Effect of population density of Phalaris minor on production potential of wheat (Triticum aestivum). Indian Journal of Agronomy 57(2012): 157161.

23. Khera KL, Sandhu BS, Aujla TS, Singh BC and Kumar K Performance of Wheat (Triticum aestivum) in Relation to Small Canary Grass (Phalaris minor) Under Different Levels of Irrigation, Nitrogen and Weed Population. Indian Journal of Agricultural Science 65.10(1995): 717-722.

24. Lovelli S, Perniola M, Ferrara A, Amato M and Di Tommaso T. Photosynthetic response to water stress of pigweed (Amaranthus retroflexus) in a southernMediterranean area. Weed Science 58(2010): 126-131.

25. Mahajan G and Brar LS. Integrated Management of Phalaris Minor in Wheat: Rationale and Approaches - A Review. Agricultural Research 23.4(2002): 241-251.

26. Malik RK and Singh S. Littleseed canarygrass (Phalaris minor) resistance to isoproturon in India. Weed Technology 9(1995): 419-425.

27. Malik RK, Bhan SK and Balyan RS and Singh BV. Weed management problems in rice-wheat cropping system adoption of weed control technology in North-Western India. Indian Society of Weed Science Annual Conference, Weed Abstract (1984), p.2115.

28. Malik RK, Gill G and Hobbs PR. Herbicide resistance major issue for sustaining wheat productivity in rice-wheat cropping system in the Indo-Gangetic plains. Rice Wheat Consortium for the Indo-Gangetic Plains, Rice Wheat Consortium Research New Delhi, India, 3 (1998). p.36. 
29. Malik RK, Yadav A, Garg VK, Balyan RS, Malik YS, Malik RS and Dhawan R. Herbicide resistance-current status and research findings. Extention Bulletin CCS HAU Hisar, India, (1995) p.37.

30. Mason HE, Navabi A, Frick BL, O'Donovan JT and Spaner DM. The weed competitive ability of Canada western red spring wheat cultivars grown under organic management. Crop Science 47(2007) 1167e1176.http://dx.doi.org/10.2135/ cropsci2006.09.0566.

31. Mehmood Z, Ashiq M, Noorka IR, Ali A, Tabasum S and Iqbal MS. Chemical Control of Monocot Weeds in Wheat (Triticum aestivum L.). American Journal of Plant Sciences 5(2014): 1272-1276.

32. Mehra SP and Gill HS. Effect of temperature on germination of Phalaris minor Retz. and its competition in wheat. Agricultural Research Journal, Punjab Agricultural University 25(1988): 529-533.

33. Ni H, Moody K, Robles RP, Paller Jr EC and Lales JS Oryza sativa plant traits conferring competitive ability against weeds. Weed Science 48(2000): 200-204.

34. Noshadian H, Azizi NR, Yasari E and Kakularimi A Effects of removal time and Canary grass density on wheat yield and yield components. International Journal of Farming and Allied Sciences 3.7(2014): 733-741.

35. Om H, Kumar S and Dhiman SD. Biology and management of Phalaris minor in rice-wheat system. Crop Protection 23(2003): 1157-1168.

36. Pakeman RJ, Karley AJ, Newton AC, Morcilo L, Brooker RW and Schob C. A trait-based approach to crop-weed interactions. European Journal of Agronomy 70(2015): 22-32.

37. Pandey J and Singh R. Weed control in wheat is key to higher production. Indian farming 47.8(1997): 4-7.

38. Paswan AK, Mandal D, Kumar J and Kumar R. Influence of Weed Management Practices on Productivity of Wheat (Triticum aestivum L.) under Middle Indo-Gangetic Plains of Eastern India. International Journal of Current Microbiology and Applied Sciences 6.6(2017): 2486-2491.

39. Prasad Babu MBB and Jain V. Effects of nitrogen on competition between wheat and grassy weeds. Indian Journal of Weed Science 44.1(2012): 53-57.

40. Radosevich S, Holt J and Ghersa C. Weed ecology. 2nd ed. 1997. New York: Wiley.p.589

41. Rajput MJ, Kalwar GN and Rajput FK, Effect of duration of weed competition period on growth and yield of wheat. PROC Pak Indo-US-Weed Control Workshop, NARC, Islamabad, 1987, Pakistan March 11-14, p 55-58.

42. Ramesh K, Rao AN and Chauhan BS. Role of crop competition in managing weeds in rice, wheat, and maize in India: A review. Crop Protection 95(2017): 14-21.

43. Ranjit JD, Bellinder R, Lauren J and Doxhbury JM, Impact of Mulching on Wheat Yield and Weed Floras in the Midhills of Nepal. Nepal Agriculture Research Journal 9(2009): 2126.
44. Saito K, Azoma K and Rodenburg J. Plant characteristics associated with weed competitiveness of rice under upland and lowland conditions in West Africa. Field Crops Research 116(2010) 116, 308e317.

45. Sardana V, Mahajan G, Jabran K and Chauhan BS. Role of competition in managing weeds: An introduction to the special issue. Crop Protection 95(2017): 1-7.

46. Sharma N. Competitive ability of different Wheat varieties against Phalaris minor (Retz.) in relation to crop geometry, 2011, Thesis, Punjab Agricultural University, Ludhiana.

47. Siddiqui I, Bajwa R, Zil-e-huma and Javaid A. Effect of six problematic weeds on growth and yield of wheat. Pakistan Journal of Botany 42.4(2010): 2461-2471.

48. Singh A, Kaur R, Kang JS and Singh G. Weed Dynamics in Rice-Wheat Cropping System, Global Journal of Biology. Agriculture and Health Sciences 1(2012): 7-16.

49. Singh S, Kirckwood RC and Marshall G. Biology and control of Phalaris minor Retz (little seed canary grass) in wheat. Cropprotection 18(1999): 1-16.

50. Singh S, Malik RK, Balyan RS and Singh S. Distribution of weed flora of wheat in Haryana. Indian Journal of Weed Science 27(1995): 114-121.

51. Sinha NK, Singh D and Roy DK. Economic threshold levels of little seed canary grass in wheat in north Bihar. Indian Journal of Weed Science 41.3\&4 (2009): 154-156.

52. Thomas CG and Yaduraju NT. Competitive effects of wild oats (Avena steils sp. ludoviciana (Durr.) Nym. on ligh interception and growth of wheat, Indian Journal of Weed Science 31(1999): 56-59.

53. Tufail M, Nawaz K and Usman M. Impact of Humic acid on the Morphology and Yield of Wheat (Triticum aestivum L.). World Applied Sciences Journal 30.4(2014): 475-480.

54. Wicks GA, Ramsel RE, Nordquist PT and Schmidt JW. Impact of weed cultivars on establishment and suppression of summer annual weeds. Agronomy Journal 78(1986): 59-62.

55. Yadav MS and Dhanai CS. Effect of different doses of nitrogen and seed rate on various characters and seed yield of wheat (Triticum aestivum L.). Journal of Pharmacognosy and Phytochemistry 6.2(2017): 01-05.

56. Zystro, JP, Natalia de Leon and Tracy, WF. Analysis of traits related to weed competitiveness in sweet corn ( $Z e a$ mays L.). Sustainability 4(2012):543-560.

\section{Cite this article as:}

Amandeep Kaur, Ram Chand, A.N. Singh. Little seed canary grass (Phalaris minor Retz.) promoting own growth functional traits but suppressing of wheat crop. (Triticum aestivum L.) at vegetative stage: An ecological assessment. Annals of Plant Sciences 6.11 (2017) pp. 1742-1750.

doi: http://dx.doi.org/10.21746/aps.2017.6.11.5

Source of support: Department of Botany, Panjab University, Chandigarh-160014, India.

Conflict of interest: Nil 